\title{
Multiple-Stage Mass Spectrometric Analysis of Complex Oligosaccharide Antibiotics (Everninomicins) in a Quadrupole Ion Trap
}

\author{
Guodong Chen, Birendra N. Pramanik, Peter L. Bartner, and \\ Anil K. Saksena \\ Schering-Plough Research Institute, Kenilworth, New Jersey \\ Michael L. Gross \\ Department of Chemistry, Washington University, St. Louis, Missouri
}

\begin{abstract}
Electrospray ionization (ESI) quadrupole ion-trap tandem mass spectrometry (MS/MS) was utilized to characterize a class of complex oligosaccharide antibiotics (everninomicins) that include SCH 27899, everninomicin-D, amino everninomicin (SCH 27900), and SCH 49088 (containing a hydroxylamino-ether sugar). The addition of sodium chloride $(\sim 1 \mu \mathrm{g} / \mathrm{mL})$ facilitates the formation of abundant metal complex ions, and this was used because protonation does not readily occur for most of these compounds. The multiple-stage mass analysis $\left(\mathrm{MS}^{\mathrm{n}}\right)$ of the sodiated species provides an important series of fragment ions that are specific for sugar sequence and for some sugar-ring opening. These data suggest a general charge-remote fragmentation pattern with the sodium cation residing in a specific, central location of the sugar chain and fragmentation occurring to trim the end of the molecule. For protonated everninomicin ( $\mathrm{SCH} 27900)$, however, the proton appears to be mobile during the collisional activation process, opening different fragmentation pathways depending on the proton location. The use of water and acetonitrile with $0.1 \%$ acetic acid as the solvent in ESI-MS promotes rapid hydrolysis of the central ortho ester, resulting in the formation of abundant sodiated products that are hydrated. These product ions of the hydrated molecules are likely formed by the same charge-remote fragmentation processes as those that occur for the unhydrolyzed precursor. (J Am Soc Mass Spectrom 2002, 13, 1313-1321) (c) 2002 American Society for Mass Spectrometry
\end{abstract}

$\mathrm{E}$ verninomicins are an important group of oligosaccharide antibiotics produced by Micromonospora carbonacea [1]; these antibiotics are highly active against gram-positive bacteria including methicillin-resistant Staphylococcus aureus and vancomycinresistant enterococci [2-4]. This class of antibiotics has a complex, eight-sugar backbone with two ortho ester functionalities. Other unusual structural features include a nitrosugar, a completely substituted aromatic ester containing two chlorines, and a methylene dioxy group.

The early structural characterization work on this class of compounds made use of a Ganguly-Sarre chemical degradation procedure [5-7]. In subsequent studies by the Schering-Plough group, fast-atom bombardment (FAB) mass spectrometry (MS) was used to

Published online September 25, 2002

Address reprint requests to Dr. G. Chen, Schering-Plough Research Institute, 2015 Galloping Hill Road, Kenilworth, NJ 07033. E-mail: guodong.chen@spcorp.com

This article was presented in part at the 48th ASMS Conference on Mass Spectrometry and Allied Topics, Long Beach, CA, June, 2000. characterize everninomicins [8-14]. The limitations of FAB-MS on sector instruments for these compounds include relatively poor sensitivity and limited tandem mass spectrometry (MS/MS) capability for detailed fragmentation studies as compared to electrospray ionization (ESI) with contemporary instruments.

Recently, we employed high-resolution ESI liquid chromatography (LC)/MS to identify several impurities and degradation products of SCH 27899, one of the everninomicin components isolated from a fermentation broth [15]. The data clearly demonstrated the feasibility of using ESI-MS to analyze samples containing everninomicins.

Coupling ESI [16] with a quadrupole ion-trap mass spectrometer provides the ability to perform $\mathrm{MS}^{\mathrm{n}}$ experiments and obtain structural information [17-24]. We wish to take advantage of the MS ${ }^{\mathrm{n}}$ capability of the ion trap because it appears to be invaluable for the structural elucidation of complex molecules.

In the research reported in this article, we explore the use of ESI-MS ${ }^{n}$ in a quadrupole ion-trap mass spectrometer for structural characterization of several ever- 
ninomicins including SCH 27899 (Scheme 1, A), everninomicin-D (Scheme 3,C) [2], amino everninomicin (SCH 27900, Scheme 4, D) [25] and SCH 49088 containing a hydroxylamino-ether sugar (Scheme 6, E) [26]. The objective is to interpret the fragmentation patterns of these compounds, seen by multiple-stage MS/MS experiments $\left(E S I-M S^{n}\right)$, and to determine whether the fragmentations are structurally useful. The prospects for utilizing charge-remote fragmentation [27-30] for this class of compounds is a secondary goal.

\section{Experimental}

SCH 27899, everninomicin-D, amino everninomicin, and SCH 49088 were isolated from a fermentation broth at the Schering-Plough Research Institute, Kenilworth, NJ. The isolation procedures were described previously $[2,11,25,26]$. The samples were dissolved in HPLCgrade acetonitrile (Fisher Scientific, Fair Lawn, NJ). A small amount of $\mathrm{NaCl}(\sim 1 \mu \mathrm{g} / \mathrm{mL})$ was added to the sample solution prior to the MS analysis to facilitate the formation of abundant complex ions containing sodium ions.

All experiments were carried out on a Finnigan LCQ-deca (San Jose, CA) ion-trap mass spectrometer equipped with an ESI source. The sample solution $(\sim 5$ $\mathrm{pmol} / \mu \mathrm{L}$ ) was introduced into the ESI source by direct infusion at a flow rate of $5 \mu \mathrm{L} / \mathrm{min}$. The ESI needle was held at $4.1 \mathrm{kV}$, and a $1.4 \times 10^{5} \mathrm{~Pa}$ nitrogen sheath gas was used to stabilize the spray. The heated capillary was set at $250{ }^{\circ} \mathrm{C}$. The helium was introduced into the ion-trap to improve the trapping efficiency and also to serve as the collision gas for CID. The operational pressure after introducing helium was at $1.9 \times 10^{-3} \mathrm{~Pa}$.

The instrument was operated in the positive-ion mode with the conversion dynode voltage at $15 \mathrm{kV}$. A typical set of experimental parameters includes a maximum ion injection time of $250 \mathrm{~ms}$ and three "microscans" per analytical scan. In the MS ${ }^{\mathrm{n}}$ experiments, standard resonance excitation was employed. The $q_{z}$ value was set at 0.25 , which is typical, and the activation time was $30 \mathrm{~ms}$. The isolation width was typically at 1.5 $\mathrm{Da} /$ charge. The activation amplitude, represented as a percentage of full activation voltage, was optimized $(5-100 \%)$ to facilitate fragmentation of precursor ions.

\section{Results and Discussion}

\section{SCH 27899}

SCH 27899 (Ziracin, Scheme 1, A) is a leading drug candidate in the everninomicin family of antibiotics to treat drug-resistant microorganisms. The positive-ion ESI mass spectrum of SCH 27899 obtained in acetonitrile by direct infusion (Figure 1a) shows a base peak representing the sodiated molecule at $\mathrm{m} / \mathrm{z}$ 1652. The insert clearly indicates its isotopic pattern, consistent with the presence of two chlorine atoms in the molecule. To observe abundant sodiated molecules required

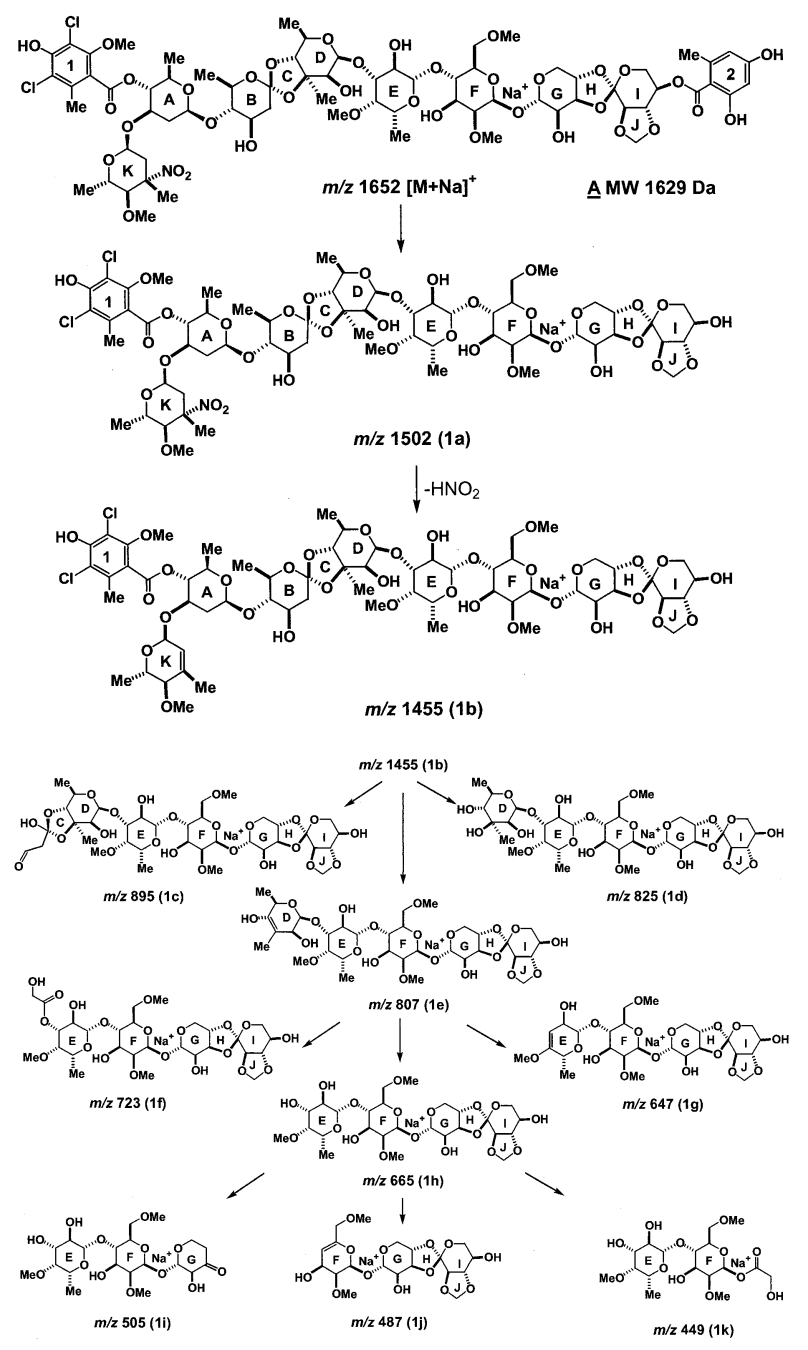

Scheme 1. Proposed key fragmentation of sodiated SCH 27899 molecules to give positive ions. Structure of SCH 27899 is shown in $A$.

the addition of $\mathrm{NaCl}$. The two ions at $\mathrm{m} / \mathrm{z} 1670$ and 1688 represented molecular ions of hydrated products of $\mathrm{SCH} 27899,\left[\mathrm{M}+\mathrm{H}_{2} \mathrm{O}+\mathrm{Na}\right]^{+}$and $\left[\mathrm{M}+2 \mathrm{H}_{2} \mathrm{O}+\mathrm{Na}\right]^{+}$, respectively. The structure of the ion at $\mathrm{m} / \mathrm{z} 1670$ representing the product for addition of one molecule of water (Scheme 2, B) is consistent with our previous report that SCH 27899 can undergo sequential hydrolysis of ortho ester functionalities [8, 11]. The initial hydrolysis occurs at the central ortho ester group (between ring $\mathrm{B}$ and $\mathrm{D}$, Scheme $\mathbf{1}, A$ ). It is likely that the presence of water in the sample and the instrument contributes to the hydrolysis process. When SCH 27899 was dissolved in a mixture of water and acetonitrile with $0.1 \%$ acetic acid, its ESI mass spectrum (Figure $1 \mathrm{~b}$ ) became quite different from that in Figure 1a. Noticeably, the base peak now represents the water-addition product ion $\left[\mathrm{M}+\mathrm{H}_{2} \mathrm{O}+\mathrm{Na}\right]^{+}$, whereas the relative abundance of sodiated SCH $27899[\mathrm{M}+\mathrm{Na}]^{+}$is much lower $(\sim 7 \%$ relative abundance in the spectrum, $\mathrm{m} / \mathrm{z}$ 1652). It appears that the solvent $\left(\mathrm{H}_{2} \mathrm{O} / \mathrm{CH}_{3} \mathrm{CN}\right)$ favors 

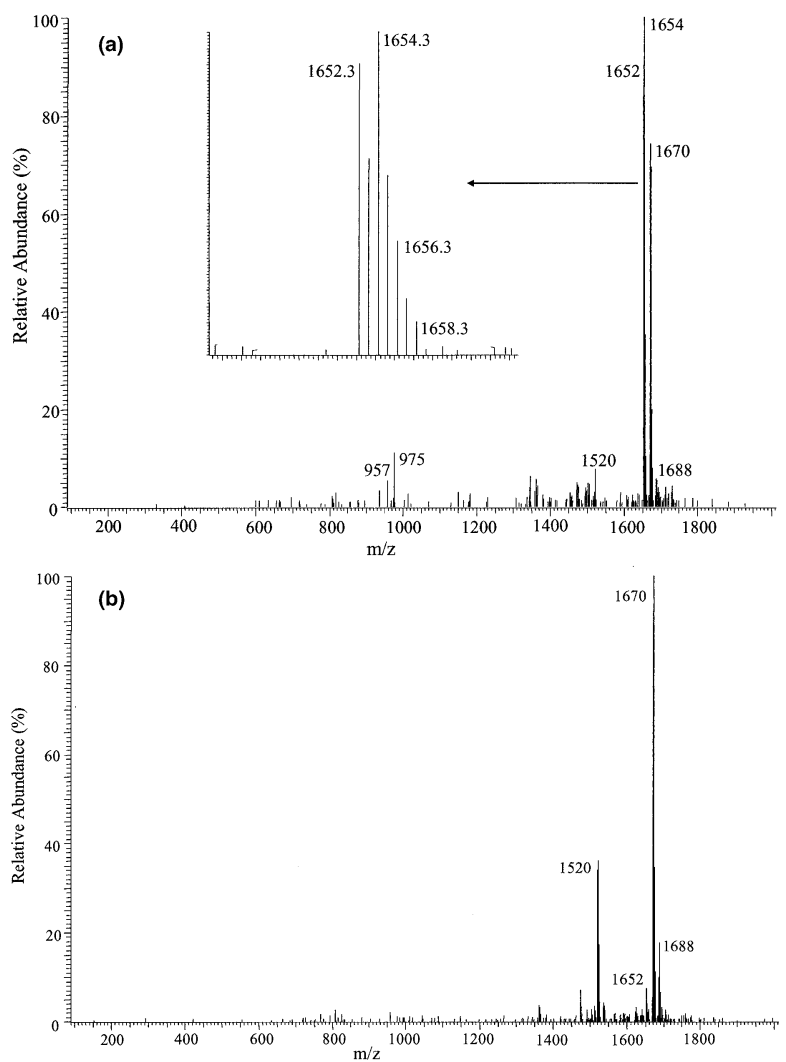

Figure 1. (a) The positive-ion ESI mass spectrum of SCH 27899 obtained in acetonitrile. The insert shows the isotopic pattern of the sodiated SCH 27899 molecule. (b) The positive-ion ESI mass spectrum of SCH 27899 obtained by using a mixture of water, acetonitrile, and $0.1 \%$ acetic acid.

the hydrolysis process, resulting in higher abundant hydrated product ions. Clearly, the appearance of ESI mass spectra of SCH 27899 is influenced by the sample preparation, and the formation of hydrated product

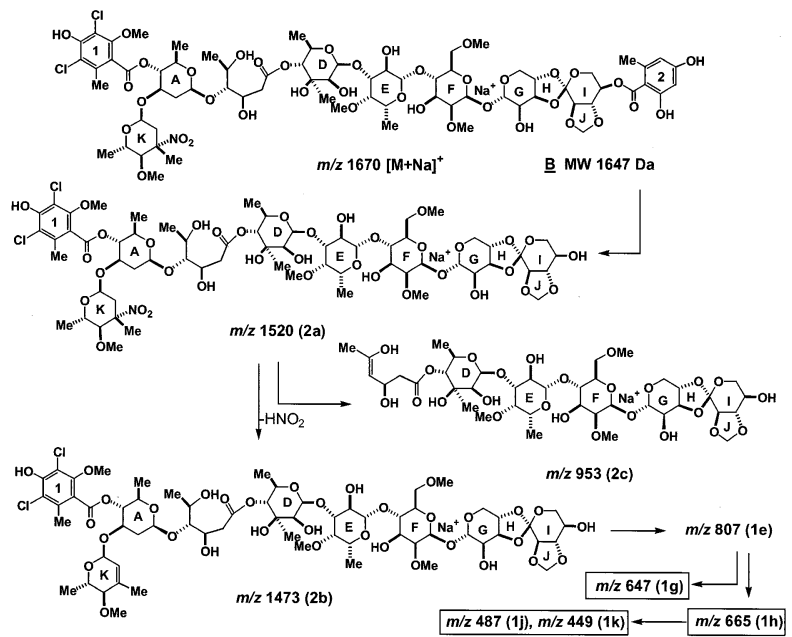

Scheme 2. Proposed key fragmentation of sodiated water-addition product of SCH 27899 to give positive ions. Structure of water-addition product of SCH 27899 is shown in $B$.
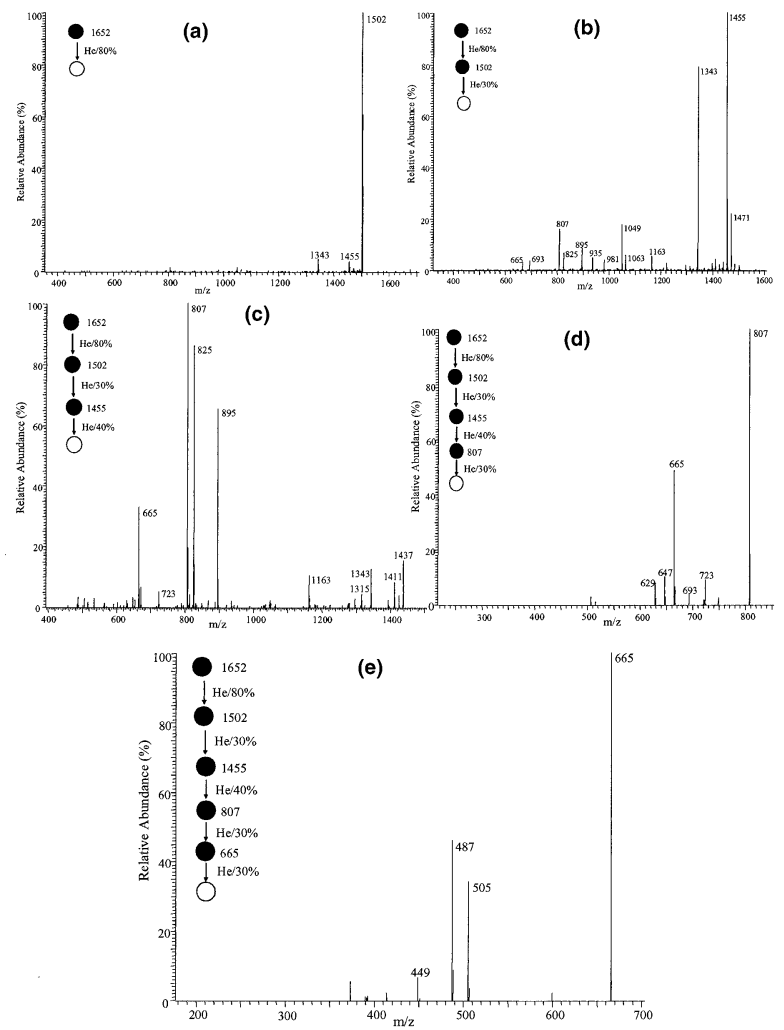

Figure 2. (a) The product-ion mass spectrum of positive ions of $m / z 1652\left([\mathrm{M}+\mathrm{Na}]^{+}\right)$for SCH 27899. (b) The product-ion mass spectrum $\left(\mathrm{MS}^{3}\right.$ ) of positive ions at $\mathrm{m} / \mathrm{z} 1502$ derived from ions at $\mathrm{m} / \mathrm{z}$ 1652. (c) The product-ion mass spectrum (MS ${ }^{4}$ ) of positive ions of $\mathrm{m} / \mathrm{z} 1455$ derived from ions of $\mathrm{m} / \mathrm{z}$ 1502. (d) The product-ion mass spectrum $\left(\mathrm{MS}^{5}\right.$ ) of positive ions of $\mathrm{m} / z 807$ derived from ions of $m / z$ 1455. (e) The product-ion mass spectrum $\left(\mathrm{MS}^{6}\right)$ of positive ions of $\mathrm{m} / \mathrm{z} 665$ derived from ions of $\mathrm{m} / \mathrm{z} 807$.

ions is a disadvantage in the structural determination of everninomicins by ESI-MS.

The generation of abundant molecular ions with limited or no fragments is consistent with the "soft" nature of the ESI process. This is in contrast to FAB mass spectra of SCH 27899 and other everninomicins, where both abundant sodiated molecules and some structurally informative fragment ions were observed [8-11, 13, 14]. Nevertheless, a reliable way of obtaining structural information is to perform tandem MS experiments on specific ions of interest.

The product-ion spectra of positive ions from sodiated SCH 27899 molecule $\left[\mathrm{M}+\mathrm{Na}^{+}\right.$at $\mathrm{m} / z 1652$ are taken upon multiple collisions in the ion-trap (Figure 2), and they clearly show one fragmentation pathway: $\mathrm{m} / \mathrm{z}$ $1652 \rightarrow \mathrm{m} / \mathrm{z} 1502 \rightarrow \mathrm{m} / \mathrm{z} 1455 \rightarrow \mathrm{m} / \mathrm{z} 807 \rightarrow \mathrm{m} / \mathrm{z} 665 \rightarrow$. The loss of ring 2 as a neutral from the sodiated $\mathrm{SCH}$ 27899 molecule $(\mathrm{m} / \mathrm{z} 1652)$ leads to the ion at $\mathrm{m} / \mathrm{z} 1502$ (Scheme 1, 1a). A subsequent loss of $\mathrm{HNO}_{2}$ from ring $\mathrm{K}$ results in the formation of an abundant ion at $m / z 1455$ (1b), which, when further activated by collisions, produces a number of sodiated ions with that of $\mathrm{m} / \mathrm{z} 807$ (1e) being the most abundant. This ion possibly represents a penta-saccharide (ring D through ring I), gener- 
ated by the cleavage of the central ortho ester function (ring C). The further fragmentation of the $m / z 807$ ion (Figure 2d) generates a product ion of $m / z 665$ (1h), which yields ions at $m / z 505$ (1i), 487 (1j), and 449 (1k). These proposed fragmentation pathways suggest that the sodium cation resides between ring $F$ and $G$. It is important to note that this location is relatively rich in oxygen atoms, consistent with the oxyphilic nature of the alkali metal ions. A similar trimming by CID was found in studies of the central calcium-binding site in peptides [31]. The ends of the molecule were cut away to reveal the site of metal-ion binding.

As can be seen in Figure 2 and Scheme 1, a simple cleavage of sugar ether linkages can also produce a series of other ions at $m / z 1315,1049,935,825$ (1d), and $647(\mathrm{~g})$ that define the sugar sequences in the molecule. The loss of ring $\mathrm{K}$ from ion of $\mathrm{m} / \mathrm{z} 1455$ (1b) with addition of a proton can produce the ion of $\mathrm{m} / \mathrm{z} 1315$. The successive losses of the substituted benzenecarboxy group (ring 1) and ring $\mathrm{K}$ bearing the oxygen from $\mathrm{m} / \mathrm{z}$ 1502 (1a) could produce the fragment ion of $m / z 1049$. The ion at $m / z 935$ possibly represents sugar ring $\mathrm{B}$ through $\mathrm{I}$, which is formed by the loss of $(1-(\mathrm{C}=\mathrm{O})-\mathrm{O}-\mathrm{A}-\mathrm{O}-\mathrm{K})$ moiety from $1 \mathrm{a}$. In addition, the opening of sugar rings leads to several structurally characteristic fragment ions. For example, the ions at $\mathrm{m} / \mathrm{z} 723$ (1f) and 693 (opening of ring D from 1e) are results of possible bond cleavages in sugar ring $D$. The ion of $\mathrm{m} / \mathrm{z} 1343$ is likely to be formed by the loss of $\mathrm{HNO}_{2}$ and subsequent opening of ring $\mathrm{K}$ to produce a sodiated O-formyl ion $(\mathrm{H}-(\mathrm{C}=\mathrm{O})-\mathrm{O}-\mathrm{A} \sim \sim)$ from $1 \mathrm{a}$.

Similar $\mathrm{MS}^{\mathrm{n}}$ analysis was also performed on wateraddition product of SCH 27899, $\left[\mathrm{M}+\mathrm{H}_{2} \mathrm{O}+\mathrm{Na}\right]^{+}$at $\mathrm{m} / \mathrm{z} 1670$ (data not shown). Its fragmentation, illustrated in Scheme 2, yields two key product ions that define the hydrolysis site between ring B and C: Ions of $\mathrm{m} / \mathrm{z} 953$ (2c) and 807 (1e). The corresponding ions for sodiated SCH 27899 are $m / z 935$ and 807, respectively. The shift of the $m / z 935$ ion to $m / z 953$ (2c) indicates that one molecule of water added along the right portion of the molecule starting from ring B. Correspondingly, the lack of shift of the $m / z 807$ ion suggests that the addition site is between ring $\mathrm{B}$ and $\mathrm{C}$. The sodium cation in the water-addition product of SCH 27899 appears to bind between rings $F$ and $G$, as revealed by the fragmentation studies, viz. the observation of ions at $\mathrm{m} / \mathrm{z} 487$ (1j) and 449 (1k). As in the case of sodiated SCH 27899, sodiated hydrated molecules dissociated to yield sugar sequence-specific product ions [i.e., ions of $\mathrm{m} / \mathrm{z} 1520$ (2a), 1333 (loss of ring $\mathrm{K}$ from 2a), 1315 (loss of $\mathrm{H}_{2} \mathrm{O}$ from $m / z$ 1333), and 1067 (loss of $1-(\mathrm{C}=\mathrm{O})-\mathrm{O}$ moiety from $m / z$ 1315)] along with some ring-opened product ions [i.e., $m / z 999$ (representing sugar ring D through I and part of sugar ring A) and $449(1 \mathrm{k})]$.

The sodium cation does not appear to be mobile under the conditions of low-energy collisional activation, a situation that contrasts with the low-energy fragmentations of protonated peptides [32]. With a stable, "fixed" site for the charged sodium for these
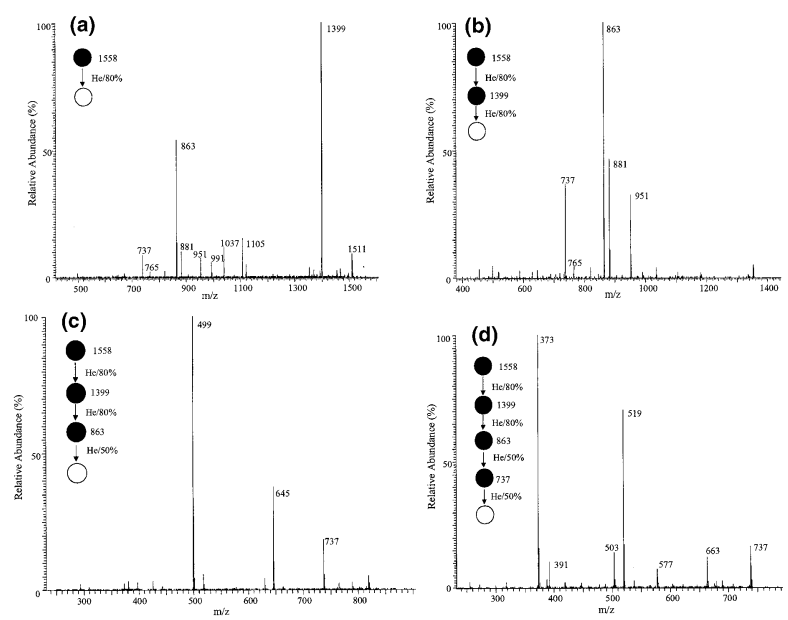

Figure 3. (a) The product-ion mass spectrum of positive ions of $m / z 1558\left([\mathrm{M}+\mathrm{Na}]^{+}\right)$for everninomicin-D. (b) The product-ion mass spectrum $\left(\mathrm{MS}^{3}\right.$ ) of positive ions of $\mathrm{m} / \mathrm{z} 1399$ derived from ions of $m / z$ 1558. (c) The product-ion mass spectrum $\left(\mathrm{MS}^{4}\right)$ of positive ions of $\mathrm{m} / \mathrm{z} 863$ derived from ions of $\mathrm{m} / \mathrm{z} 1399$. (d) The product-ion mass spectrum $\left(\mathrm{MS}^{5}\right.$ ) of positive ions of $\mathrm{m} / \mathrm{z} 737$ derived from ions of $m / z 863$.

everninomicins, the fragmentations are likely to be charge-remote [27-30, 33-35]. The results from the ion-trap experiments are distinctively different from the previous FAB-MS data obtained by using sector instruments [8-10, 13, 14]; under high-energy collisions, the sodium cation appears to be mobile when attached to everninomicins, resulting in mass spectra different from those we see here. It is notable that low-energy collisions in an ion-trap mass spectrometer are a richer source of informative fragmentation for this class of compounds.

\section{Everninomicin-D}

Everninomicin-D is a main component of the isolated fermentation broth [2]. As for SCH 27899, everninomicin-D gave an abundant sodiated molecule $[\mathrm{M}+\mathrm{Na}]^{+}$ at $m / z 1558$ upon ESI (data not shown). In addition, two ions of $\mathrm{m} / \mathrm{z} 1576$ and 1594 result from addition of one and two molecules of water: $\left[\mathrm{M}+\mathrm{H}_{2} \mathrm{O}+\mathrm{Na}\right]^{+}$and $\left[\mathrm{M}+2 \mathrm{H}_{2} \mathrm{O}+\mathrm{Na}\right]^{+}$, respectively. The presence of adventitious traces of water in the sample contributed to the hydration process because no aqueous solvent was used during the experiment.

A four-stage mass analysis of the sodiated everninomicin-D $[\mathrm{M}+\mathrm{Na}]^{+}$at $m / z 1558$ illustrates a dominant fragmentation pathway: $m / z 1558 \rightarrow m / z 1399 \rightarrow m / z$ $863 \rightarrow m / z 737 \rightarrow$ (Figure 3 ). The loss of $\mathrm{HNO}_{2}$ from ring $\mathrm{K}$ results in a product ion of $m / z 1511$ (3a) and a further loss of $112 \mathrm{Da}$, likely to be $\mathrm{CH}_{3}-\mathrm{CH}=\mathrm{C}\left(\mathrm{OCH}_{3}\right)-\mathrm{C}$ $\left(\mathrm{CH}_{3}\right)=\mathrm{CH}_{2}$, from the fragmentation of ring $\mathrm{K}$ leads to the ion of $m / z 1399$ (3b; Figure 3a). The product ion of $m / z 1399$ produces an abundant $m / z 863$ ion (3c), which defines the right portion of the molecule from the central ortho ester group (ring C) (Figure 3b). Further 

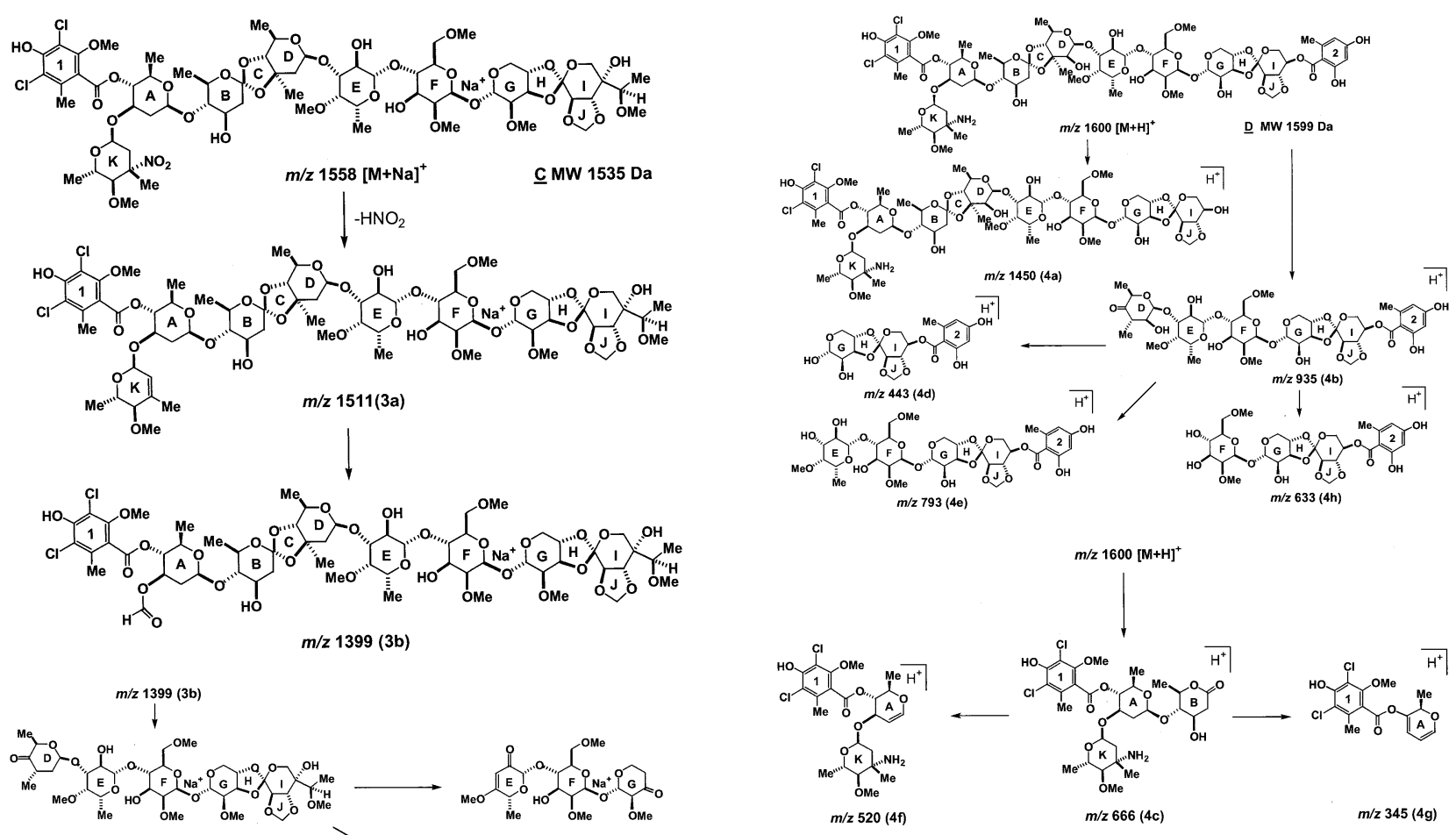

Scheme 4. Proposed key fragmentation of protonated amino everninomicin molecules to give positive ions. Structure of amino everninomicin is shown in $D$.

part of ring B from 3b), 765 (opening of ring D from 3c), and $663(3 \mathrm{~g})]$.

The incorporation of a sodium cation in the complex molecule causes the subsequent fragmentation to be rich in information. Once again, the "fixed" sodium site in the metal complex ion opens the door to chargeremote processes.

Scheme 3. Proposed key fragmentation of sodiated everninomicin-D molecules to give positive ions. Structure of everninomicin-D is shown in $C$.

fragmentation of $\mathrm{m} / \mathrm{z} 863$ yields product ions of $\mathrm{m} / \mathrm{z} 737$ (3e), 645 (3d), and 499 (3f) (Figure 3c; Scheme 3).

Upon further activation, the ion at $\mathrm{m} / \mathrm{z} 737$ generates a number of higher generation product ions, including those of $m / z 663$ (3g), 577 (3h), 503 (loss of rings H, I, J from $3 \mathrm{e}$ ), 391 (opening of rings $\mathrm{E}, \mathrm{H}$ and loss of rings I and J from 3e), and 373 (3j) (Figure 3d; Scheme 3). This fragmentation pathway clearly indicates that the sodium cation in the complex ion is located between ring F and G, as discussed previously for SCH 27899. As in the case of SCH 27899, low-energy multiple collisions of sodiated everninomicin-D also generate both sugar sequence-specific ions (i.e., of $\mathrm{m} / \mathrm{z} 1105$, representing sugar ring A through I, Scheme 3), 991 (loss of ring A from $\mathrm{m} / \mathrm{z}$ 1105), 881 (loss of ring B from $\mathrm{m} / \mathrm{z}$ 991), and ions formed by sugar-ring opening [i.e., of $\mathrm{m} / \mathrm{z} 1037$ (loss of rings 1, K, and part of ring $\mathrm{A}$ from sodiated everninomicin-D molecule), 951 (loss of rings 1, A, and

\section{Amino Everninomicin}

Amino everninomicin is a minor component isolated from the fermentation broth [25]. Compared with $\mathrm{SCH}$ 27899 , SCH 27900 has a primary amine group instead of the nitro function on sugar $\mathrm{K}$ (Scheme 4, D). This change in a functional group leads to significant changes in the appearance of the ESI mass spectrum (Figure 4). The base peak in the spectrum corresponds to the protonated molecule $[\mathrm{M}+\mathrm{H}]^{+}$at $\mathrm{m} / z$ 1600, whereas the sodiated molecule $[\mathrm{M}+\mathrm{Na}]^{+}$at $\mathrm{m} / z 1622$ forms at lower abundance. This contrasts with the ESI mass spectra of SCH 27899 and everninomicin-D, for which the dominant ions are sodiated molecules.

The product-ion spectrum of the protonated molecule $[\mathrm{M}+\mathrm{H}]^{+}$at $m / z 1600$ (Figure 5a) shows a base peak at $m / z 666$ (4c), which defines the left portion of the molecule starting at the central ortho ester group (ring C). Another fragment, that of $m / z 935$ (4b), provides the information on the right portion of the molecule starting at the central ortho ester group. Further fragmentation of the ion at $m / z 666$ yields some product ions that are specific for the sugar sequence, such as those of $\mathrm{m} / \mathrm{z}$ 


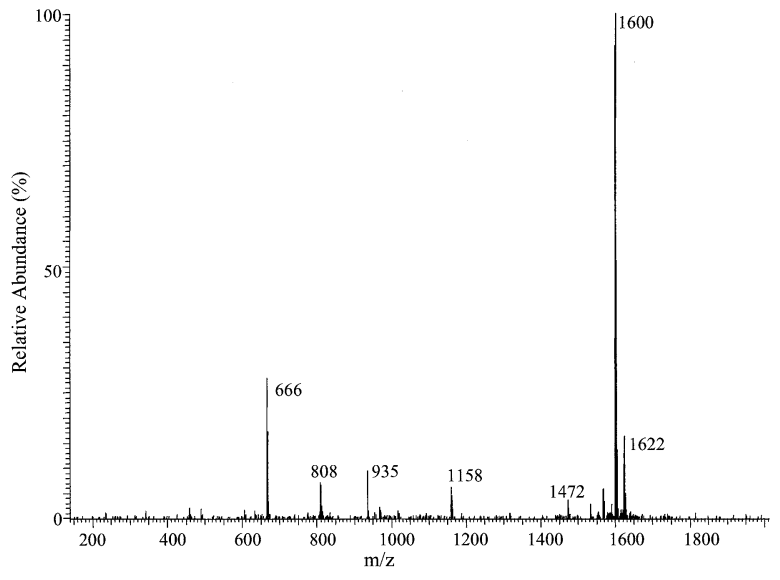

Figure 4. The positive-ion ESI mass spectrum, obtained in acetonitrile, of amino everninomicin.

520 (4f), 345 (4g), and 233 (ring 1) (Figure 5b; Scheme 4). The product-ion spectrum of $\mathrm{m} / \mathrm{z} 935$ shows a series of sugar sequence-specific ions of $m / z 793$ (4e), 633 (4h), $443(4 \mathrm{~d})$, and 293 (loss of ring 2 from $4 \mathrm{~d}$ ) (Figure 5c). The fragmentation patterns, illustrated in Scheme 4, suggest that the proton in the protonated molecule appears to be mobile during the activation (similar to that for the fragmentation of peptides [32]) and results in the formation of a complex array of fragment ions that are specific for sugar sequence.

When the sodium cation was incorporated into the molecule, the complex ion fragmented to generate a dominant ion at $\mathrm{m} / \mathrm{z} 1472$ (5a) as a result of loss of ring 2 (Figure 6a). Its further fragmentation produces a number of product ions that are specific for sugar sequence at $m / z 1315$ (loss of ring $\mathrm{K}$ from $5 \mathrm{a}$ ), 1065 (loss of substituted carboxy ring 1 from $\mathrm{m} / \mathrm{z}$ 1315), 825 (1d), 807 (1e), 665 (1h), and 487 (1j) (Figure 6b). Some fragment ions formed via ring opening are of $\mathrm{m} / \mathrm{z} 895$ (1c) and 723 (1f). The product-ion at $m / z$ 665, when

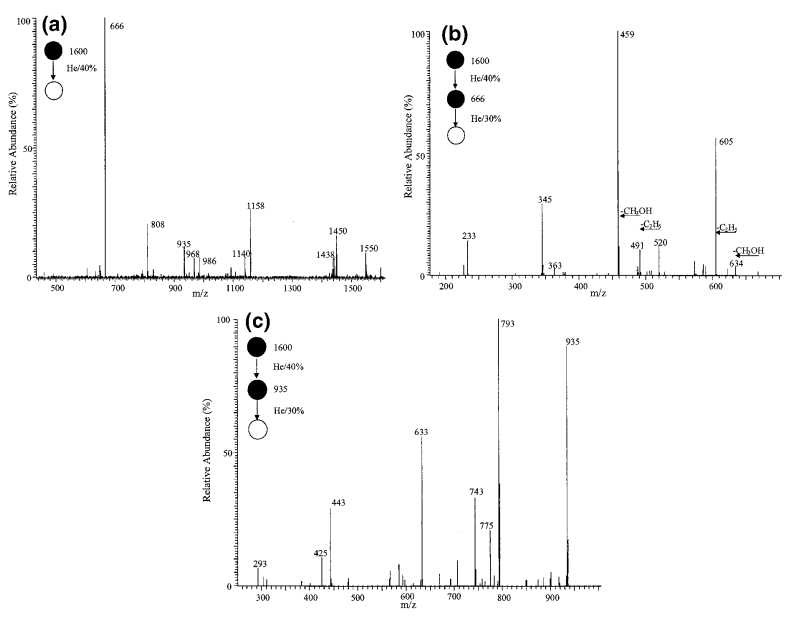

Figure 5. (a) The product-ion mass spectrum of positive ions of $m / z 1600\left([\mathrm{M}+\mathrm{H}]^{+}\right)$for amino everninomicin. (b) The product-ion mass spectrum $\left(\mathrm{MS}^{3}\right.$ ) of positive ions of $m / z 666$ derived from ions of $m / z$ 1600. (c) The product-ion mass spectrum $\left(\mathrm{MS}^{3}\right)$ of positive ions of $\mathrm{m} / \mathrm{z} 935$ derived from ions of $\mathrm{m} / \mathrm{z} 1600$.

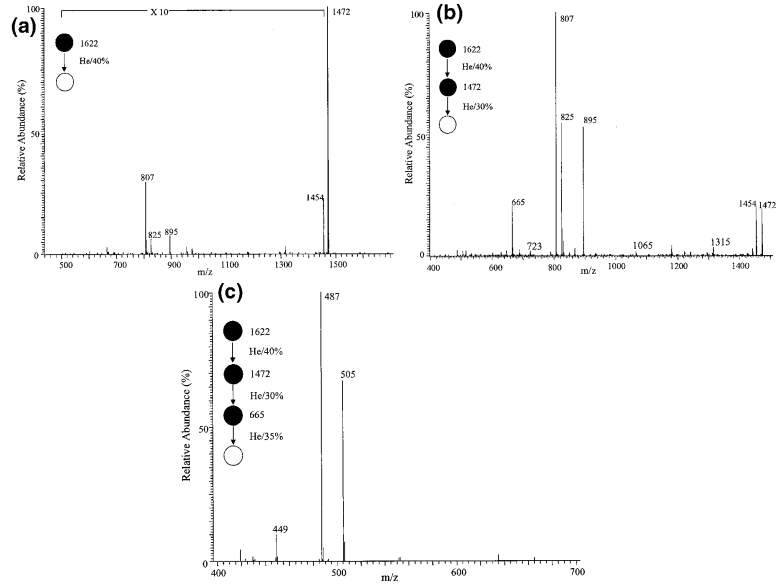

Figure 6. (a) The product-ion mass spectrum of positive ions of $m / z 1622\left([\mathrm{M}+\mathrm{Na}]^{+}\right)$for amino everninomicin. (b) The production mass spectrum $\left(\mathrm{MS}^{3}\right.$ ) of positive ions at $\mathrm{m} / \mathrm{z} 1472$ derived from ions at $m / z$ 1622. (c) The product-ion mass spectrum $\left(\mathrm{MS}^{4}\right)$ of positive ions at $\mathrm{m} / \mathrm{z} 665$ derived from ions of $\mathrm{m} / \mathrm{z} 1472$.

submitted to further collisional activation, gives several sub-product ions at $\mathrm{m} / \mathrm{z} 505$ (1i), 487, and 449 (1k) (Figure 6c), as summarized in Scheme 5.

As for the other sodiated everninomicin molecules (SCH 27899, everninomicin-D), the sodium cation is likely to be located between rings $F$ and $G$, binding to ring $F$ and $G$ through the three oxygen atoms. The observed fragmentations of the sodiated molecule for this everninomicin are also likely charge-remote. For this class of analytes, the sodiated molecules generate both sequence-specific fragment ions and ring-opening fragment ions, whereas the protonated molecules generally give sequence-specific fragment ions.

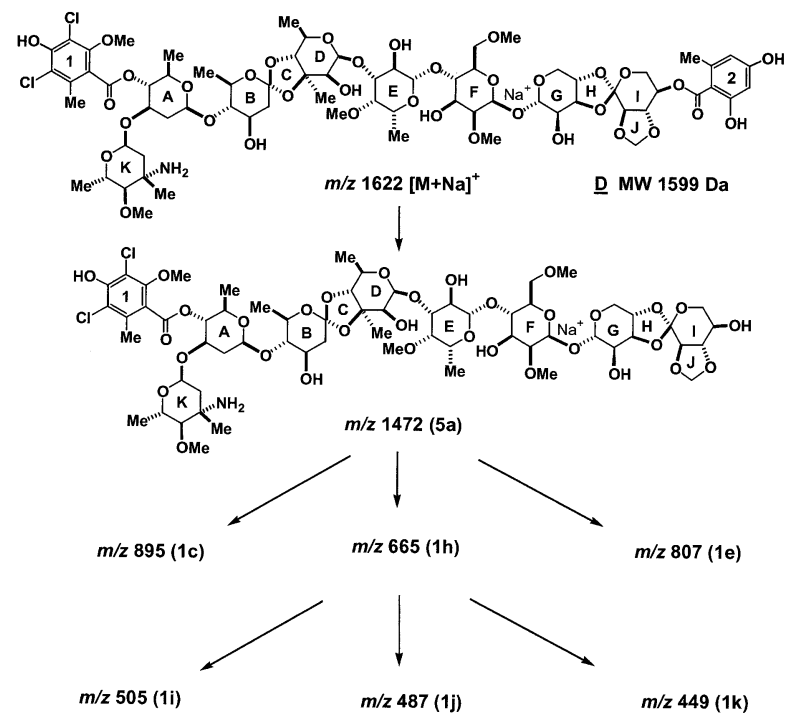

Scheme 5. Proposed key fragmentation of sodiated amino everninomicin molecules to give positive ions. 


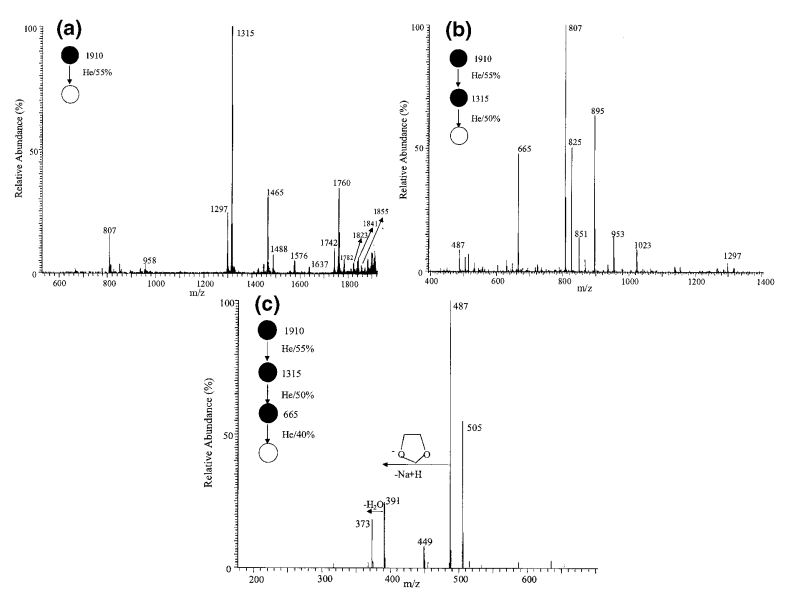

Figure 7. (a) The product-ion mass spectrum of positive ions of $m / z 1910\left([\mathrm{M}+\mathrm{Na}]^{+}\right)$for $\mathrm{SCH} 49088$. (b) The product-ion mass spectrum $\left(\mathrm{MS}^{3}\right)$ of positive ions at $\mathrm{m} / \mathrm{z} 1315$ derived from ions of $\mathrm{m} / \mathrm{z}$ 1910. (c) The product-ion mass spectrum $\left(\mathrm{MS}^{4}\right)$ of positive ions at $m / z 665$ derived from ions of $m / z 1315$.

\section{SCH 49088}

SCH 49088 is a newly isolated everninomicin antibiotic containing a unique O-alkylated hydroxylamine substituted sugar subunit [26]. The positive-ion ESI mass spectrum shows a base peak at $\mathrm{m} / \mathrm{z} 1910$, corresponding to the sodiated molecule $[\mathrm{M}+\mathrm{Na}]^{+}$(data not shown). Additionally, an abundant molecular ion of the hydrated material, $\left[\mathrm{M}+\mathrm{H}_{2} \mathrm{O}+\mathrm{Na}\right]^{+}$at $m / z 1928$ provides evidence for some hydrolysis.

The three-stage mass spectrometric analysis of the sodiated molecule $\left[\mathrm{M}+\mathrm{Na}^{+}\right.$at $\mathrm{m} / \mathrm{z} 1910$ (Figure 7a) shows that several product ions arise in the high mass region, including those of $\mathrm{m} / \mathrm{z} 1855,1841,1823$, and 1782. The losses of $\mathrm{C}_{4} \mathrm{H}_{7}(55 \mathrm{u})$ and $\mathrm{C}_{5} \mathrm{H}_{9}(69 \mathrm{u})$ from the side chain of the O-alkylated hydroxylamine subunit likely produce ions of $\mathrm{m} / \mathrm{z} 1855$ and 1841, respectively. A further loss of water and $\mathrm{C}_{2} \mathrm{H}_{3} \mathrm{O}_{2}(59 \mathrm{u})$ from the ion of $\mathrm{m} / \mathrm{z} 1841$ leads to those of $\mathrm{m} / \mathrm{z} 1823$ and 1782, respectively. Other fragment ions related to the loss of side chain of O-alkylated hydroxylamine subunit of the sodiated molecule include those of $\mathrm{m} / \mathrm{z} 1637$ and 1576. The loss of both the side chain of O-alkylated hydroxylamine subunit and ring $\mathrm{K}$ leads to an ion at $\mathrm{m} / \mathrm{z} 1465$ (6b). Structural information on the side chain of the hydroxylamine subunit is very much evident in the fragmentation of the sodiated molecules. A ready loss of a species containing ring 2 from the complex ion generates the ion of $\mathrm{m} / \mathrm{z} 1760$ (6a). Its further dissociation yields the ions of $\mathrm{m} / \mathrm{z} 1488$ (loss of side chain of O-alkylated hydroxylamine subunit) and 1315 (6c). Further activation of the $\mathrm{m} / \mathrm{z} 1315$ ion produces a number of structurally informative product ions (Figure $7 \mathrm{~b}$ ), including sugar sequence-specific ions [i.e., of $\mathrm{m} / \mathrm{z} 953$ (6d), 825 (1d), 665 (1h), 487 (1j)], and sugar ring-opening ions [i.e., of $\mathrm{m} / \mathrm{z} 1023$ (loss of ring 1 and part of ring $\mathrm{A}$ from 6c), 895 (1c), 851 (loss of ring A and part of ring $B$ from $\mathrm{m} / \mathrm{z}$ 1023), and 807 (1e)].

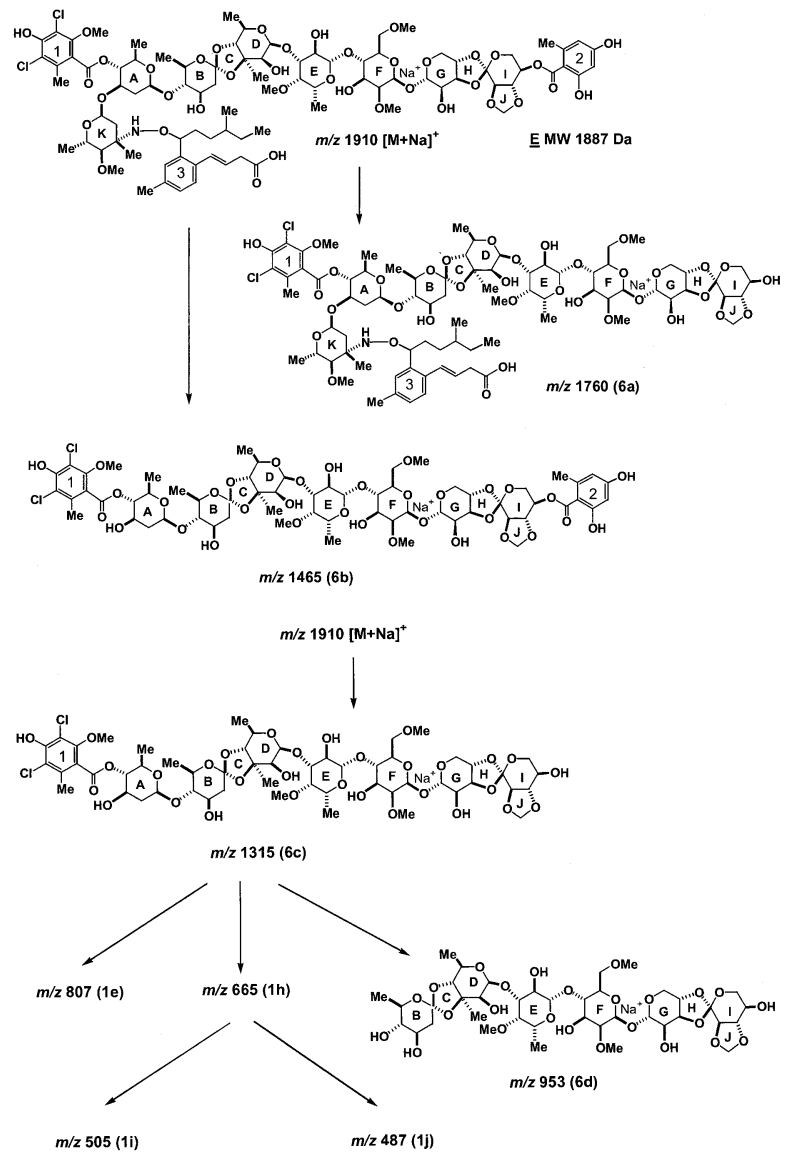

Scheme 6. Proposed key fragmentation of sodiated SCH 49088 molecules. Structure of SCH 49088 is shown in E.

The fragmentation of the $m / z 665$ ion establishes the location of sodium cation to be between rings $\mathrm{F}$ and $\mathrm{G}$ (Figure 7c; Scheme 6). The observed fragmentation is again best explained as charge-remote for this sodiated molecule.

\section{Conclusions}

Using ESI-MS and ESI-MS ${ }^{\mathrm{n}}$, we characterized several complex oligosaccharides (everninomicins) in a quadrupole ion-trap. The choice of solvent in sample preparation determines the appearance of the ESI mass spectra. The sodiated water-addition product of $\mathrm{SCH}$ 27899 is dominant when SCH 27899 is prepared in a mixture of water and acetonitrile with $0.1 \%$ acetic acid. Abundant sodiated molecules of everninomicin-D and SCH 49088 form under ESI conditions in the presence of acetonitrile, whereas the protonated molecule is the major ion that forms for amino everninomicin.

The ESI-MS ${ }^{\mathrm{n}}$ studies have provided detailed structural information on these compounds. In general, the sodiated molecules appear to undergo charge-remote fragmentations with the sodium cation "locked" between sugar rings F and G. Fragment ions that are likely specific for the sugar sequence and for ring-opening are formed. On the other hand, protonated molecules for 
the amino everninomicin fragment to yield more complicated fragmentation patterns.

We demonstrated that the detailed fragmentation patterns obtained from ESI-MS ${ }^{\mathrm{n}}$ studies are valuable for structural elucidation of other related everninomicins. Several characteristic fragment ions are observed to be associated with changes on certain functional groups in the everninomicins. For example, a loss of ring 2 is a common process when the ring 2 is attached to the sugar ring I. A loss of $\mathrm{HNO}_{2}$ from the various molecular ions indicates the presence of a nitro group. The recent development of successful total synthesis of SCH 27899 [36-38] and the preparation of semi-synthetic analogues for biological investigations through solution and solid-phase combinatorial chemistry [39] underscore the need for characterizing this class of compounds. ESI-MS ${ }^{\mathrm{n}}$ should provide an effective means to meet this need for these compounds and their modified analogs.

\section{Acknowledgments}

This research was supported in part by the National Center for Research Resources of the NIH (grant no. P41RR00954) and by Schering-Plough Research Institute. The authors thank Drs. V. Girijavallabhan, J. Piwinski, and A. K. Ganguly for their support of this project.

\section{References}

1. Weinstein, M. J.; Wagman, G. H.; Oden, E. M.; Luedemann, G. M.; Sloane, P.; Murawski, A.; Marquez, J. Purification and Biological Studies of Everninomicin B. Antimicrob. Agents Chemother. 1965, 5, 821-827.

2. Girijavallabhan, V. M.; Ganguly, A. K. Wiley: New York, 1992; 4th ed.; p 259. Kirk-Othmer Encyclopedia of Chemical Technology, Vol. III.

3. Ganguly, A. K.; McCormick, J. L.; Saksena, A. K.; Das, P. R.; Chan, T.-M. Chemical Modifications and Structure Activity Studies of Ziracin and Related Everninomicin Antibiotics. Bioorg. Med. Chem. Lett. 1999, 9, 1209-1214.

4. Foster, D. R.; Rybak, M. J. Pharmacologic and Bacteriologic Properties of SCH 27899 (Ziracin), an Investigational Antibiotic from the Everninomicin Family. Pharmacotherapy 1999, 19, 1111-1117.

5. Ganguly, A. K.; Sarre, O. Z.; Greeves, D.; Morton, J. Structure of Everninomicin D-1. J. Am. Chem. Soc. 1975, 97, 1982-1985.

6. Ganguly, A. K.; Szmulewicz, S. Structure of Everninomicin C. J. Antibiot. 1975, 28, 710-712.

7. Ganguly, A. K.; Saksena, A. K. Structure of Everninomicin B. J. Antibiot. 1975, 28, 707-709.

8. Ganguly, A. K.; Pramanik, B. N.; Girijavallabhan, V. M.; Sarre, O.; Bartner, P. L. The Use of Fast Atom Bombardment Mass Spectrometry for The Determination of Structures of Everninomicins. J. Antibiot. 1985, 38, 808-812.

9. Pramanik, B. N.; Ganguly, A. K. Fast Atom Bombardment Mass Spectrometry: A Powerful Technique for Study of Oligosaccharide Antibiotics. Indian J. Chem. 1986, 25B, 1105-1111.

10. Pramanik, B. N.; Das, P. R. Molecular Ion Enhancement Using Salts in FAB Matrices for Studies On Complex Natural Products. J. Nat. Prod. 1989, 52, 534-546.

11. Ganguly, A. K.; Pramanik, B. N.; Chan, T.-M.; Liu, Y.-H.; Morton, J.; Girijavallabhan, V. M. The Structure of New
Oligosaccharide Antibiotics, 13-384 Components 1 and 5 . Heterocycles 1989, 28, 83-88.

12. Ganguly, A. K.; McCormick, J. L.; Chan, T.-M.; Saksena, A. K.; Das, P. R. Determination of the Absolute Stereochemistry at the C16 Orthoester of Everninomicin Antibiotics; a Novel Acid-Catalyzed Isomerization of Orthoesters. Tetrahedron Lett. 1997, 38, 7989-7992.

13. Bartner, P. L.; Pramanik, B. N.; Saksena, A. K.; Liu, Y.-H.; Das, P. R.; Sarre, O.; Ganguly, A. K. Structural Elucidation of Everninomicin-6, a New Oligosaccharide Antibiotic, by Chemical Degradation and FAB-MS Methods. J. Am. Soc. Mass Spectrom. 1997, 8, 1134-1140.

14. Pramanik, B. N.; Bartner, P. L.; Chen, G. The Role of Mass Spectrometry in the Drug Discovery Process. Curr. Opin. Drug Discov. Dev. 1999, 2, 401-417.

15. Shipkova, P. A.; Heimark, L.; Bartner, P. L.; Chen, G.; Pramanik, B. N.; Ganguly, A. K.; Cody, R. B.; Kusai, A. HighResolution LC/MS for Analysis of Minor Components in Complex Mixtures: Negative Ion ESI for Identification of Impurities and Degradation Products of a Novel Oligosaccharide Antibiotic. J Mass Spectrom. 2000, 35, 1252-1258.

16. (a)Fenn, J. B.; Mann, M.; Meng, C. K.; Wong, S. F.; Whitehouse, C. M. Electrospray Ionization for Mass Spectrometry of Large Biomolecules. Science 1989, 246, 64-71.(b)Ganguly, A. K.; Pramanik, B. N.; Chen, G.; Shipkova, P. A. Characterization of Pharmaceuticals and Natural Products by Electrospray Ionization Mass Spectrometry. In Applied Electrospray Mass Spectrometry; Pramanik, B. N.; Ganguly, A. K.; Gross, M. L., Eds.; Marcel Dekker: New York, 2002; pp 149-185.

17. March, R. E.; Hughes, R. J. Quadrupole Storage Mass Spectrometry. Wiley: New York, 1989.

18. March, R. E.; Todd, J. F. J. Practical Aspects of Ion Trap Mass Spectrometry. CRC Press: Boca Raton, 1995.

19. Cooks, R. G.; Chen, G.; Weil, C. Quadrupole Mass Filters and Quadrupole Ion Traps. In Selected Topics in Mass Spectrometry in the Biomolecular Sciences; Caprioli, R. M.; Malorni, A.; Sindona, S., Eds.; Kluwer Academics Publishers, 1997;213-238.

20. Lin, T.; Glish, G. L. C-Terminal Peptide Sequencing via Multistage Mass Spectrometry. Anal. Chem. 1998, 70, 51625165.

21. Ngoka, L. C. M.; Gross, M. L. Multistep Collisionally Activated Decomposition in an Ion Trap for the Determination of the Amino-Acid Sequence and Gas-Phase Ion Chemistry of Lithium-Coordinated Valinomycin. Int. J. Mass Spectrom. 2000, 194, 247-259.

22. Shen, J.; Brodbelt, J. S. Post-Column Metal Complexation of Quinolone Antibiotics in a Quadrupole Ion Trap. Rapid Commun. Mass Spectrom. 1999, 13, 1381-1389.

23. Gaucher, S. P.; Leary, J. A. Determining Anomericity of the Glycosidic Bond in $\mathrm{Zn}$ (II)-Diethylenetriamine-Disaccharide Complexes Using $\mathrm{MS}^{\mathrm{n}}$ in a Quadrupole Ion Trap. J. Am. Soc. Mass Spectrom. 1999, 10, 269-272.

24. McLuckey, S. A.; Stephenson, J. L. Ion/Ion Chemistry of High-Mass Multiply Charged Ions. Mass Spectrom. Rev. 1998, 17, 369-407.

25. Ganguly, A. K.; Girijavallabhan, V. M.; Miller, G. H.; Sarre, O. Z. Chemical Modification of Everninomicins. J. Antibiot. 1982, 35, 561-570.

26. Saksena, A. K.; Jao, E.; Murphy, B.; Schumacher, D.; Chan, T.-M.; Puar, M. S.; Jenkins, J. K.; Maloney, D.; Cordero, M.; Pramanik, B. N.; Bartner, P.; Das, P. R.; McPhail, A. T.; Girijavallabhan, V. M.; Ganguly, A. K. Structure Elucidation of SCH 49088, a Novel Everninomicin Antibiotic Containing an Unusual Hydroxylamino-Ether Sugar, Everhydroxylaminose. Tetrahedron Lett. 1998, 39, 8441-8444. 
27. Tomer, K. B.; Crow, F. W.; Gross, M. L. Location of Double Bond Position in Unsaturated Fatty Acids by Negative Ion MS/MS. J. Am. Chem. Soc. 1983, 105, 5487-5488.

28. Jensen, N. J.; Tomer, K. B.; Gross, M. L. Gas-Phase Ion Decomposition Occurring Remote to a Charge Site. J. Am. Chem. Soc. 1985, 107, 1863-1868.

29. Adams, J. Charge-Remote Fragmentations: Analytical Applications and Fundamental Studies. Mass Spectrom. Rev. 1990, 9, 141-186.

30. Gross, M. L. Charge-Remote Fragmentations: Method, Mechanism and Applications. Int. J. Mass Spectrom. Ion Proc. 1992, 118/119, 137-165.

31. Nemirovskiy, O. V.; Gross, M. L. Determination of Calcium Binding Sites in Gas-Phase Small Peptides by Tandem Mass Spectrometry. J. Am Soc. Mass Spectrom. 1998, 9, 1020-1028.

32. Dongre, A. R.; Jones, J. L.; Somogyi, A.; Wysocki, V. H. Influence of Peptide Composition, Gas-Phase Basicity, and Chemical Modification on Fragmentation Efficiency: Evidence for the Mobile Proton Model. J. Am. Chem. Soc. 1996, 118, 8365-8374.

33. Cheng, C.; Giblin, D.; Gross, M. L. Structural Determination of Oxofatty Acids by Charge-Remote Fragmentations. J. Am. Soc. Mass Spectrom. 1998, 9, 216-224.

34. Domingues, M. R. M.; Nemirovskiy, O. V.; Marques, M. G. O. S.; Neves, M. G.; Cavaleiro, J. A. S.; Ferrer-Correia,
A. J.; Gross, M. L. High- and Low-Energy Collisionally Activated Decompositions of Octaethylporphyrin and its Metal Complexes. J. Am. Soc. Mass Spectrom. 1998, 9, 767-774.

35. Cerny, R. L.; MacMillan, D. K.; Gross, M. L.; Mallams, A. K.; Pramanik, B. N. Fast-Atom Bombardment and Tandem Mass Spectrometry of Macrolide Antibiotics. J. Am. Soc. Mass Spectrom. 1994, 5, 151-158.

36. Nicolaou, K. C.; Mitchell, H. J.; Suzuki, H.; Rodriguez, R. M.; Baudoin, O.; Fylaktakidou, K. C. Total Synthesis of Everninomicin 13,384-1 Part 1: Synthesis of the A(1)B(A)C Fragment. Angew. Chem. Int. Ed. 1999, 38, 3334-3339.

37. Nicolaou, K. C.; Rodriguez, R. M.; Fylaktakidou, K. C.; Suzuki, H.; Mitchell, H. J. Total Synthesis of Everninomicin 13,384-1 Part 2: Synthesis of the FGHA(2) Fragment. Angew. Chem. Int. Ed. 1999, 38, 3340-3345.

38. Nicolaou, K. C.; Mitchell, H. J.; Rodriguez, R. M.; Fylaktakidou, K. C.; Suzuki, H. Total Synthesis of Everninomicin 13,384-1 Part 3: Synthesis of the DE Fragment and Completion of the Total Synthesis. Angew. Chem. Int. Ed. 1999, 38, 33453350 .

39. Nicolaou, K. C.; Mitchell, H. J.; Fylaktakidou, K. C.; Suzuki, H.; Rodriguez, R. M. 1,2-Seleno Migrations in Carbohydrate Chemistry: Solution and Solid-Phase Synthesis of 2-Deoxy Glycosides, Orthoesters, and Allyl Orthoesters. Angew. Chem. Int. Ed. 2000, 39, 1089-1093. 